\section{Áreas protegidas, educación para la diversidad biocultural y extensión universitaria}

\author{
Laura Ruth Nudelman \\ Instituto de Educación Física Dr. Jorge E. \\ Coll N 9-016, Argentina. \\ lauranudelman14373@gmail.com \\ (iD) orcid.org/0000-0003-0290-5957

\section{Gabriela Diaz} \\ Universidad Nacional de Cuyo, Argentina. \\ gdiaz@infoar.net \\ (iD) orcid.org/0000-0001-6821-3473
}

RECEPCIÓN: 29/06/21

ACEPTACIÓN FINAL:08/09/21

\section{Resumen}

El propósito del siguiente artículo es hacer un análisis teórico desde el paradigma de la extensión crítica sobre un proyecto en territorio de la Universidad Nacional de Cuyo realizado entre 2016 y 2018 , enmarcado en el tema de la educación ambiental dentro de las áreas naturales protegidas en la provincia de Mendoza, República Argentina. Se razonan desde la perspectiva de la "extensión crítica freiriana" la planificación, ejecución y evaluación de resultados del proyecto llevado a cabo. Se busca contribuir a un diagnóstico de la extensión crítica en las áreas naturales protegidas de Mendoza y la relación de los/ as guardaparques como actores claves en la educación ambiental para la biodiversidad.

Palabras clave: extensión crítica; pedagogía freiriana; guardaparques; pobladores rurales; diversidad biocultural.

\section{Alexandra Daiana Barahona}

Universidad Nacional de Cuyo - Consejo

Nacional de Investigaciones Científicas

y Técnicas. Gobierno de la provincia de

Mendoza, Argentina.

alexibarahona@gmail.com

(iD) orcid.org/0000-0002-6928-1272
Ambiente y extensión universitaria /

Intervenciones

다(1)(잉

\section{Carina Llano}

Universidad Nacional de Cuyo - Consejo Nacional de Investigaciones Científicas y Técnicas, Argentina. Ilano.carina@gmail.com (iD) orcid.org/0000-0003-2744-5133
Protected areas, biocultural diversity education, university extension

\section{Abstract}

The following article proposes a theoretical analysis from the critical extension paradigm on a territorial project carried out by

Universidad Nacional de Cuyobetween2016 and 2018, framed on the subject of environment al education with in protected natural areas in the province of Mendoza, in the Argentine Republic. Wean alyze from the perspective of the "critical Freirian extension" the planning, execution and evaluation of theresults of the project carried out. Its eeks to contribute to ananalysis of the critical extension in the protected natural areas of Mendoza, and the relation ship of park rangers as keyactors in environment al education for biodiversity.

Keywords: critical extension; freirian pedagogy; parkranger; rural people; biocultural diversity.
Áreas naturais protegidas, educação para a diversidade biocultural e extensão universitária

\section{Resumo}

O seguinte artigo propõe uma análise teórica a partir do paradigma da extensão crítica sobre um projeto territorial da Universidade Nacional de Cuyo realizado entre 2016 e 2018, enquadrado no tema da educação ambiental em áreas naturais protegidas na província de Mendoza, na República Argentina. Analisamos sob a ótica da "extensão freiriana crítica" o planejamento, execução e avaliação dos resultados do projeto realizado. Busca contribuir para um diagnóstico da extensão crítica nas áreas naturais protegidas de Mendoza, e a relação dos guardas-florestais como atores-chave na educação ambiental para a biodiversidade.

Palavras-chave: extensão crítica; pedagogia freiriana; guarda-florestal; população do campo; diversidade biocultural.

Para citación de este artículo: Nudelman, L.R.; Diaz, G.; Barahona, A.D. y Llano, C. (2021). Áreas protegidas, educación para la diversidad biocultural y extensión universitaria. +E: Revista de Extensión Universitaria, 11(15), e0013. doi: 10.14409/extension.2021.15.Jul-Dic.e0013 


\section{Introducción}

La extensión universitaria es un campo de disputa y de reflexión respecto del modo de realizar prácticas en el territorio con diversos actores sociales. En un contexto donde el medio ambiente es un elemento troncal, el siguiente trabajo busca realizar un aporte a partir del análisis teórico-práctico de un proyecto en territorio de la Universidad Nacional de Cuyo (UNCUYO) llevado a cabo entre los años 2016 y 2018, donde integrantes de instituciones de educación pública e investigación se involucraron en el diálogo con sectores que trabajan dentro de las áreas naturales protegidas (en adelante ANPs) en la provincia de Mendoza, Argentina, en torno al eje temático de la educación ambiental para la biodiversidad (sensu Gonzalez Gaudiano, 2002).

Los actores claves del sistema de ANPs son los/as guardaparques. Ellos/as son los/as responsables de la educación ambiental dentro de las áreas y en las zonas de influencia. Los/as destinatarios/as de esas acciones son visitantes, turistas, instituciones educativas de la provincia y particularmente las escuelas rurales cercanas.

En primer lugar, se describe brevemente el proyecto llevado a cabo. Luego se indaga el corpus bibliográfico referido a la extensión crítica latinoamericana de la Universidad de la República de Uruguay (UdelaR) en calidad de referente y miembro de la Unión Latinoamericana de Extensión Universitaria (ULEU). Se continúa con el análisis de la extensión crítica a partir de la revisión de las concepciones de educación ambiental y extensión en el marco legal que ordena y rige el funcionamiento de las ANPs de Mendoza. Se busca diagnosticar, desde la perspectiva de la "extensión crítica freiriana" (Tommasino y Hegedüs, 2006; Tommasino y Cano, 2016), la planificación, ejecución y evaluación de resultados del proyecto realizado. Finalmente, se plantean reflexiones y perspectivas.

\section{Descripción del proyecto ${ }^{1}$}

"Encuentro de miradas sobre educación ambiental para la biodiversidad en áreas protegidas de Mendoza" es un proyecto que se realizó durante los años 2017 y 2018 luego quedar seleccionado en la Primera Convocatoria de Proyectos en Territorio de la UNCUYO. El mismo se enmarca en el proyecto 06M096 "Educación ambiental para la sustentabilidad: relación entre diversidad biológica y cultural" de la Secretaría de Ciencia Técnica y Posgrado de la misma universidad.

Participó en él un equipo de trabajo interdisciplinario, colaborativo e interinstitucional. Las instituciones que confluyeron en dicha labor fueron la UNCUYO, el CONICET y el Instituto de Educación Física (IEF) Dr. Jorge E. Coll N 9-016, con aval y apoyo de la Dirección de Recursos Naturales Renovables (DRNR) de la provincia de Mendoza. Dicho equipo estuvo

1) Financiamiento obtenido de proyectos "Educación ambiental para la sustentabilidad: relación entre diversidad biológica y cultural" M096 SeCTyPUNCuyo (2016-2018); "Encuentro de miradas sobre educación ambiental para la biodiversidad en áreas protegidas de Mendoza" I Convocatoria de proyectos en el territorio, Secretaría de Desarrollo Institucional y Territorial, UNCuyo (2018); "Educación para la diversidad biocultural en Mendoza" EU35-UNCU9282 SeCTyPUNCuyo (2018-2019); "Conocimiento ecológico local sobre biodiversidad en la zona de influencia de tres áreas protegidas de la provincia de Mendoza (Argentina)". 06/M108 SIIP UNCuyo (2018-2020).

Agradecemos a las personas revisoras por las sugerencias que permitieron incorporar mejoras sustanciales al manuscrito. 
conformado por estudiantes e investigadoras de diversas disciplinas. ${ }^{2}$ En detalle, el trabajo fue llevado a cabo por una comunicadora social, una geógrafa (ambas estudiantes de posgrado), tres biólogas, una socióloga y estudiante de la Tecnicatura Superior en Conservación de la Naturaleza, y una estudiante de Trabajo Social. Se sumaron en sus etapas algunos/as estudiantes de esta Tecnicatura como colaboradores/as.

El proyecto se centró en el sistema de ANPs de la provincia de Mendoza y su importancia para la conservación de la diversidad biológica y cultural. Los/as actores claves del sistema son los/as guardaparques, dado que por ley, y de hecho, se les adjudica la responsabilidad de la educación ambiental en las ANPs y las zonas de influencia, lo cual alcanza a visitantes, turistas y a las escuelas rurales cercanas y de la provincia. Se seleccionaron seis ANPs: Bosques Telteca, Reserva de Biósfera Ñacuñán, Laguna del Diamante, La Payunia, Laguna de Llancanelo y Caverna de las Brujas. La primera está ubicada en el noreste; la segunda, en el centro-este; la tercera, en el centro-oeste; y las tres últimas, en el sur de la provincia (Figura 1). Estas representan una herramienta no solo de conservación sino de defensa de bienes comunes y se encuentran en permanente tensión, con amenazas y desafíos urgentes para lograr la conservación de la biodiversidad y una mejor calidad de vida para los/as pobladores/as locales (Cannizzo et al., 2021).

Figura 1. Localización de las ANPs mencionadas en el texto

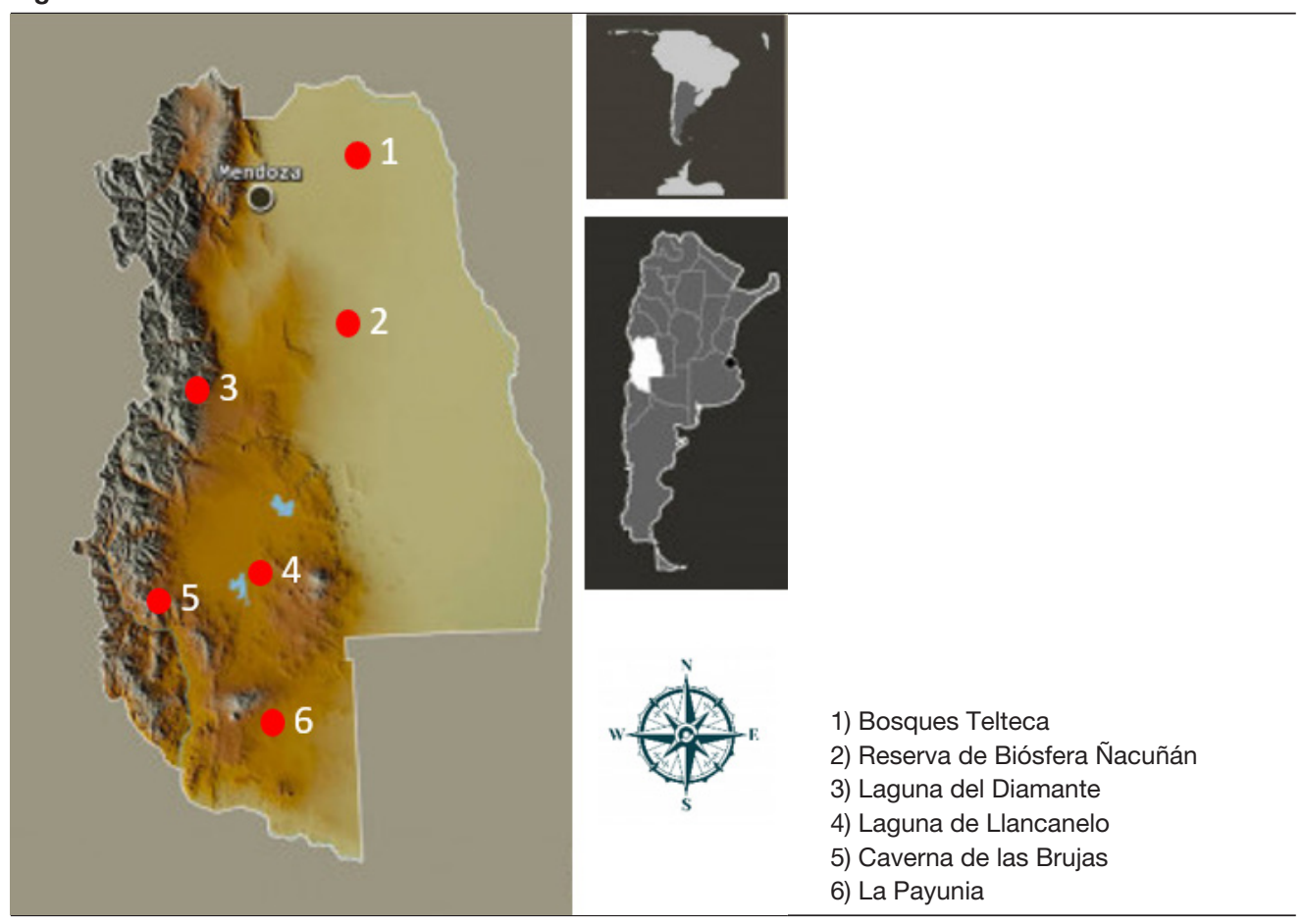

Fuente: elaboración propia, 2021. 
Uno de los objetivos de este proyecto fue fortalecer las habilidades y capacidades de los/as guardaparques como educadores/as ambientales, para lo cual se abordó la falta de reconocimiento social de su rol y las diversas problemáticas que ellos/as identifican en la conservación de la diversidad biológica y cultural. Mediante la reflexión y la adquisición de conceptos y herramientas por los/as guardaparques tanto en ejercicio como en formación (estudiantes de la Tecnicatura en Conservación de la Naturaleza), se pretendió reflexionar sobre sus acciones en educación ambiental para la biodiversidad, ya sea en el ámbito escolar como más allá de la escuela. ${ }^{3}$ Para ello se emplearon diversas técnicas tanto cuantitativas como cualitativas: tradicionales (como encuestas semiestructuradas) y participativas (como talleres con mapeo de actores y teatro foro).

Se realizaron dos talleres en cada una de las seis áreas protegidas de Mendoza mencionadas con un total de 54 participantes, donde se problematizaron y construyeron saberes sobre educación ambiental, diversidad biológica y cultural junto a los actores sociales de la Dirección de Recursos Naturales Renovables (Figura 2). Previo a los encuentros y durante el primer taller, se hicieron encuestas a los y las guardaparques y se relevó un total de 64 respuestas. Las mismas indagaron las concepciones y representaciones sociales sobre educación para la biodiversidad (Barahona et al., 2021). En la primera instancia se sistematizaron las actividades de educación ambiental efectuadas en los últimos cinco años en cada una de las reservas, y en la segunda se hizo devolución y validación de los datos relevados y analizados y se pusieron a disposición herramientas para elaborar proyectos de educación ambiental. Se aplicaron técnicas de Investigación-Acción Participativa (IAP) y se distribuyeron en el equipo roles móviles: mientras algunas integrantes dinamizaron, otras observaron y registraron.

Por último, se realizaron dos instancias de sesión de retroalimentación (Llosa, 2000), una al norte de la provincia, en la Reserva Bosques Telteca, con 10 participantes, y una al extremo sur, en la Reserva Caverna de las Brujas, con 14 participantes. Allí se encontraron guardaparques de las diversas ANPs y técnicos/as de la DRNR para intercambiar experiencias mediante la modalidad de conversatorio, validar los resultados y evaluar el ciclo de talleres.

Este proyecto poseyó una orientación de asesoría técnica pero no se redujo a una transferencia de conocimientos sino a la proyección de acciones de educación ambiental para la diversidad biológica y cultural desde un paradigma participativo, donde los/as guardaparques tuvieron un rol central.

Figura 2. Articulación del equipo de investigación y extensión y los/as actores sociales

\begin{tabular}{|c|c|c|}
\hline $\begin{array}{l}\text { EQUIPO DE INVESTIGACIÓN } \\
\text { Y EXTENSIÓN }\end{array}$ & \multirow{4}{*}{$\stackrel{\text { Articulación }}{\longleftrightarrow}$} & $\begin{array}{l}\text { ACTORES SOCIALES } \\
\text { Dirección de Recursos Naturales Renovables }\end{array}$ \\
\hline Universidad Nacional de Cuyo & & Cuerpo de Guardaparques \\
\hline $\begin{array}{l}\text { Instituto de Investigación de Zonas } \\
\text { áridas (IADIZA_CONICET) }\end{array}$ & & Equipo de Gestión \\
\hline $\begin{array}{l}\text { Tecnicatura en conservación de la } \\
\text { Naturaleza (IEF N9 } 016 \text { Sede Malargüe) }\end{array}$ & & Equipo técnico \\
\hline
\end{tabular}

3) El término "más allá de la escuela" fue acuñado como elemento superador de la discusión teórica e histórica que alude a los ámbitos de enseñanza tradicionalmente denominados como formales, no formales e informales (Sirvent et al., 2010). 


\section{La extensión crítica en clave latinoamericana}

La extensión es una función que la universidad pública argentina posee en su esquema de trabajo desde la Reforma de Córdoba en el año 1918, más allá de los tipos de acciones que engloba dicho concepto.

La extensión universitaria es un término polisémico que, según cómo se entienda, es asumido como vinculación, articulación, transferencia cultural o tecnológica, entre la universidad y la sociedad (Tommasino y Cano, 2016).

En América Latina, dos modelos de extensión caracterizaron principalmente la actividad extensionista: el "difusionista o transferencista" y el de la "extensión crítica".

La extensión crítica es una función característica de la universidad latinoamericana, diferenciada de aquella de corte germánica academicista o norteamericana orientada al mercado, donde se entiende que el campo de la educación superior en sentido amplio debe necesariamente interactuar con el medio, construir puentes y contribuir a resolver problemas de la sociedad.

Si bien esta intencionalidad de interacción y de resolución de problemáticas sociales puede ser explícita y manifiesta, es probable que existan tradiciones institucionales y dispositivos que reproduzcan acciones del modelo transferencista.

Como afirman dos intelectuales uruguayos comprometidos con la extensión crítica (Tommasino y Cano):

"Ambos modelos difieren en sus orígenes, sus supuestos pedagógicos, sus horizontes ético-políticos, en cómo definen y qué lugar asignan a los interlocutores sociales de las experiencias de extensión, y en cómo definen (explícita o implícitamente) a la extensión en sí misma y en relación a las demás funciones de la universidad". (2016, p. 16)

El modelo "difusionista o transferencista" está asociado a una transferencia unidireccional y vertical de tecnologías y conocimientos científicos construidos por fuera de las comunidades a las que van dirigidos, con el objeto de desarrollarlos y aumentar su rendimiento productivo. Desde la óptica de las ciencias sociales, se asocia con el asistencialismo higienista y educativo bancario. Existe un supuesto donde la alteridad no universitaria es solo capaz de aprender en un sentido bancario y, por lo tanto, de consumir ideas y no de crearlas. Aquí también subyace el supuesto de que los portan las respuestas y las mejores resoluciones son quienes provienen del mundo académico. Como lo expresan Tommasino y Cano:

"la característica definitoria es la transferencia de saberes y tecnologías desde la universidad hacia la sociedad, con el objetivo de lograr cambios en la conducta, hábitos o procedimientos de un determinado grupo social en relación a determinado tipo de actividad (productiva, social, sanitaria, etcétera)". (2016, p. 14)

Desde el modelo de la extensión crítica, nutrido por las reflexiones de Paulo Freire, se asume este modo de hacer extensión como un ejercicio de ecología de saberes (Sousa Santos, 2006), donde la universidad es un actor más en la producción de conocimiento y en la construcción conjunta de estrategias con otros actores para resolver problemáticas sociales. Esta función de extensión también entiende otra forma de aprender por fuera de las aulas universitarias, como parte de la trayectoria educativa, donde la sensibilización, el ponerse en contacto y dialogar con las problemáticas de los otros, interpela a trabajar en 
conjunto desde un profundo sentido humanista. Parafraseando a Slaughter y Leslie (1999, en Tommasino y Cano, 2016):

"Se trata de una disputa que no puede ser saldada administrativamente, y que en cambio interesa sostener, evidenciando las implicaciones políticas de los modos en que se conciben y organizan los procesos de vinculación universidad-sociedad. Para ello, importa distinguir entre las discusiones conceptuales que buscan actualizar la concepción crítica de la extensión como proceso pedagógico transformador, de las articulaciones discursivas que buscan destituir dicho sentido crítico, subsumiendo a la extensión en las concepciones, modos y gramáticas de los procesos universitarios hegemónicos en el contexto del 'capitalismo académico'”. (p. 6)

En este sentido, la función extensionista permite fortalecer vínculos con organizaciones y comunidades, y con la docencia y la investigación, así como promover el desarrollo académico situado en torno a determinadas problemáticas. Comienza aquí un ciclo cuyo objetivo primordial ha sido denominado, según el contexto, como curricularización de la extensión o de integralidad de funciones de docencia, investigación y extensión (UdelaR, 2010, en Tommasino y Cano, 2016).

Tommasino y Hegedüs (2006) definen y defienden el tipo de extensión vinculada al paradigma de la educación popular de Paulo Freire y la IAP que abreva de la tradición de Fals Borda. La misma es definida como "extensión crítica" en Uruguay y como "extensión popular" en las universidades brasileñas (Falcao, 2006, en Tommasino y Cano, 2016).

El equipo del proyecto "Encuentro de miradas" se centró en visibilizar que no necesariamente por realizar una intervención expositiva en escuelas rurales se concretaba una experiencia de educación ambiental para la biodiversidad, sino que requería una clara intencionalidad pedagógica, un proceso de planificación, sistematización y evaluación del proceso. Al respecto:

"Es necesaria una concepción pedagógica y dialógica que incorpore esta dimensión del trabajo extensionista a la tarea educativa en torno a la cual se reúnen estudiantes y docentes. También lo es generar las condiciones de seguimiento, monitoreo y evaluación de los procesos extensionistas, favoreciendo una perspectiva de la sistematización y evaluación basada en el aprendizaje colectivo". (Tommasino y Cano, 2016, p. 15).

Entonces, el desafío consistió en interpelar a los/as guardaparques desde este enfoque pedagógico. Sin embargo, el proyecto no se planteó como extensión crítica debido a que en la bibliografía actual y el espacio académico se enfatiza la extensión desde el ámbito universitario principalmente entre alumnos/as universitarios/as y docentes. La novedad de este proyecto fue el diálogo de manera predominante entre investigadoras y guardaparques.

Quienes diseñaron el proyecto fueron investigadoras, docentes y estudiantes de la universidad pública, con incursiones en diversos proyectos de extensión desde un enfoque más aproximado a la extensión crítica. Poder colocar en diálogo el proyecto "Encuentro de miradas" y realizarle preguntas desde distintas dimensiones puede ser de utilidad para conocer las fortalezas y debilidades para futuras iniciativas.

Entre las fortalezas estuvo el generar espacios de reflexión sobre Educación Ambiental para la Biodiversidad (EAB), lo cual permitió visibilizar y valorar la necesidad del mismo.

Entre las debilidades se identificó el vacío de procesos de sistematización de las experien- 
cias educativas para la diversidad biológica y cultural, así como la inexistencia de un espacio de encuentro instituido con continuidad para intercambiar dichas experiencias. Mediante las metodologías empleadas, se evidenció además la contradicción entre las voluntades particulares y las lógicas y costumbres institucionales, lo que se manifestó en las acciones individuales de asistir, participar en los talleres y capitalizar desde la experiencia personal, pero sin poder construir estrategias conjuntas entre diversos estamentos de la institución.

\section{La extensión crítica en las ANPs de Mendoza}

La provincia de Mendoza reúne una red de 19 ANPs provinciales, sin contar aquellas municipales que también existen, lo que representa alrededor del $13 \%$ de la superficie del territorio provincial. En todas ellas no solo está el cuerpo de guardaparques, sino que otros actores se vinculan en su interior o en la zona buffer, más conocida como "zona de amortiguación". Estos actores hacen uso del área para vivir y satisfacer derechos humanos fundamentales: de vivienda, alimento, trabajo, educación, recreación, espirituales, entre otros.

Si se revisa la ley provincial 6045/93 de Áreas Protegidas, se deben considerar ciertos artículos que nos dan pistas para entender la extensión crítica como una función que puede ayudarnos a pensar estrategias de acción a corto, mediano y largo plazo, desde la formación de guardaparques y técnicos/as en conservación de la naturaleza con un enfoque de relación con las comunidades.

En su artículo 5, que versa sobre los objetivos generales de la ley, inciso II) expresa: "promover la participación de los integrantes de la comunidad en forma directa a través de los órganos que la representen"; y en su inciso m): "promover, facilitar y realizar acciones relacionadas con la educación ambiental y su difusión".

Estos artículos habilitan a pensar la interacción con las comunidades desde órganos representativos. Sin embargo, al avanzar en la lectura de la ley no existe claridad en la concepción sobre "educación y cultura" con referencia a los modos de usar y aprovechar los ambientes naturales.

En este sentido, en su artículo 17, inciso b), determina entre las acciones a realizar dentro de las ANPs aquellas de educación y cultura, a las cuales define como:

"las orientaciones para enseñar lo relativo al manejo, utilización y aprovechamiento de los elementos y características existentes en los ambientes naturales, y las dirigidas a promover el conocimiento de las riquezas naturales e históricas y valores propios de una región o territorio y la necesidad de conservarlos".

En este inciso no se explicita quién enseña a quién, o si se trata de un aprendizaje mutuo entre diversos actores.

En cuanto a la categorización de las ANPs en el territorio mendocino, la categoría II de Reserva Natural Cultural es aquella que expresamente promueve la participación de las comunidades. Según el artículo 35 de la ley provincial 6045, incluye aquellas áreas naturales en las que se encuentran comunidades aborígenes interesadas en preservar sus propias pautas culturales, las tierras y recursos vivos que poseen, y en ellas hay una estrecha dependencia del hombre con respecto al medio natural, ya sea en cuanto a su alimentación, abrigo u otras necesidades materiales para su subsistencia. 
Para lo cual deberán, conforme continúa el texto del artículo: "promover la participación de las comunidades que las habitan en la elaboración y seguimiento de estos planes" y "fomentar la implementación de proyectos de desarrollo y la constitución de cooperativas y otras formas de organización de la comunidad".

Es necesario entender que las ANPs en la provincia poseen no más de 70 años, y en muchos casos en esos territorios han vivido varias generaciones de pobladores/as y pueblos originarios y han alcanzado más de cien años de ocupación. Ello está comprendido en el artículo 49:

"Cuando se hallaren en las zonas protegidas asentamientos humanos anteriores a la promulgación de la presente ley, la autoridad de aplicación deberá considerarla dentro de los planes de manejo, regularizar su condición jurídica, garantizar la continuidad de su actividad y promover la integración económica a las actividades de mantenimiento y desarrollo de las áreas protegidas". (ley 6045/93)

Asume como criterio interpretativo principal armonizar los fines conservacionistas de las ANPs con los aspectos sociales implicados. También se tendrán en cuenta la antigüedad del asentamiento, la calidad evidenciada en el manejo de los recursos naturales y el grado de importancia que la actividad reviste para los ingresos del poblador.

El artículo 59 establece la incidencia del Instituto Argentino de Investigaciones de Zonas Áridas (IADIZA) como autoridad legítima en la elaboración y evaluación de los planes de manejo. Y contempla en el inciso e) "planes de educación ambiental, de extensión a través de experiencias demostrativas sobre manejo y gestión de integración de recursos y de integración de poblaciones locales".

La ley de Áreas Protegidas, entonces, considera la participación de las comunidades por intermedio de un consejo creado con diversas instituciones, el reconocimiento de la presencia de pobladores/as previa a la existencia de las ANPs y el fomento de actividades de educación ambiental en conjunto con el IADIZA.

Se toma como ejemplo la necesidad de promover la extensión crítica y tener en cuenta otros actores más allá de los/as técnicos/as, guardaparques e investigadores/as, esto es, la presencia de productores/as agropecuarios/as dentro o en la zona buffer de las ANPs de Mendoza. En algunos casos viven dentro de las Áreas Naturales, como la Reserva Natural y Cultural Bosques Telteca, en el departamento de Lavalle, y la Reserva Natural La Payunia en Malargüe, o poseen sitios de invernada o veranada dentro del ANPs, como en la Reserva Castillos de Pincheira, también en Malargüe, y Laguna del Diamante en el departamento de San Carlos; o deben atravesar la reserva para llegar a los sitios de veranada y parición, como en las Reservas Caverna de las Brujas y Laguna de Llancanelo. En la Reserva de Biósfera de Ñacuñán, las experiencias en la relación con los/as pobladores/as no está exenta de conflictos (Torres et al., 2010).

Esta situación exige articulaciones claras con diversos actores (puesteros/as en el caso de las ANPs del sur) con el fin de conservar no solo la diversidad biológica sino la cultural, pues los usos, costumbres y tradiciones de este sector poseen un valor cultural intrínseco.

Se traen a colación los planes de manejo de la Reserva Caverna de las Brujas y de Laguna de Llancanelo en el departamento de Malargüe, que expresan un modo de vincularse con la comunidad. 
La Reserva Caverna de las Brujas, desde su plan de manejo del año 2000, incorpora entre los objetivos de conservación:

"La función educativa y social permanente del área protegida y la integración de la comunidad de Malargüe al proceso de desarrollo y utilización del área protegida, remarcando su importancia tanto como Monumento Natural, como instrumento social y recurso económico de la región". (Neoambiental, 2016, p. 114)

Mientras que dentro de la Reserva Laguna de Llancanelo interactúan diversas comunidades y se cuenta con una escuela albergue de nivel primario en la zona de Carapacho.

Los límites del ANP Laguna de Llancanelo son establecidos por ley provincial 7824/07, que determina en sus objetivos conservar el patrimonio cultural y promover la participación activa de la comunidad:

"Asegurar el arraigo y conservar las pautas culturales de los/as pobladores/as locales, así como su economía, dentro de un marco de sustentabilidad ambiental brindando además alternativas de desarrollo.

Establecer mecanismos de participación comunitaria a fin de lograr una cogestión del área con los pobladores locales, municipalidad de Malargüe, las organizaciones de la sociedad civil y otros organismos públicos o privados vinculados al humedal”. (art. 4, inciso b)

La Reserva, además de ser "Reserva Natural Manejada" y "Santuario de Flora y Fauna", es categorizada como "Reserva de Paisaje Protegido" y "Reserva Natural y Cultural" en las tierras de propiedad privada, asimilando a la población local que habita históricamente en la zona como "aborigen" a los efectos de la ley 6045/93 en sus artículos 33 y 35 .

Cabe destacar que en la gestión de las ANPs en Argentina y América Latina se ha transitado desde un paradigma "preservacionista" sin gente, donde se resguarde de modo prístino e intangible el ambiente, hacia uno "conservacionista", donde se entienda al ser humano como parte del ambiente desde un enfoque ecosistémico (Cannizzo et al., 2021). Y este cambio paulatino de paradigma habilita a trabajar desde el enfoque de la extensión crítica.

\section{Guardaparques: actores claves en la educación para la diversidad biocultural}

El cuerpo de guardaparques de la provincia de Mendoza fue creado en el año 2004 a partir de la sanción de la ley provincial 7291. En su artículo $4^{\circ}$ establece como una de sus funciones "participar en la programación y ejecución de los planes de educación ambiental a implementarse en la provincia". El artículo 105 diferencia tres grandes grupos de funciones: "tareas de fiscalización, control y vigilancia", "tareas de educación y atención a visitantes" y "tareas de alto riesgo". Esta clasificación ha sido respetada al momento de sistematizar las funciones (Figura 3).

Considerando los artículos 4 y 105 se puede entender que las distintas atribuciones se encuentran interconectadas y ciertas funciones pueden devenir "funciones paraguas" de otras, donde el énfasis, esfuerzo y presupuesto en su accionar pueden colaborar a salvaguardar y alivianar otras tareas.

Otros artículos de la ley 7291 que ponen de relieve la tarea de educación ambiental son el 12 y el 17. Según el artículo 12, una de las funciones del jefe de cuerpo de guardapar- 
ques, la cual confome al artículo 17 además es función del jefe de zona, consiste en "participar en la planificación y desarrollo de programas de difusión y educación ambiental".

Figura 3. Organigrama de funciones del cuerpo de guardaparques de la provincia de Mendoza

\begin{tabular}{|c|c|c|c|}
\hline Funciones del Cuerpo de Guardapa & rques & $\longrightarrow$ & $\begin{array}{l}\text { Espacio de acción Territorio } \\
\text { Provincial y ANP de Mendoza }\end{array}$ \\
\hline $\begin{array}{l}\text { Tareas de fiscalización, } \\
\text { control y vigilancia }\end{array}$ & Tareas de alto riesgo & $\begin{array}{l}\text { Tareas de educación } \\
\text { y atención a visitante }\end{array}$ & $\begin{array}{l}\text { Colaborar a nivel nacional, provincial, } \\
\text { municipal en tareas compatibles con } \\
\text { la ley } 7.291 \text { y ley } 6.045\end{array}$ \\
\hline $\begin{array}{l}\text { - Velar por la Ley } 6.045 \\
\text { - Verificar que se cumplan los } \\
\text { planes de manejo de las ANPs } \\
\text { - Verificar documentación para } \\
\text { el ingreso a las ANPs } \\
\text { - Custodiar RRNN en ANPs } \\
\text { - Proteger Flora, Fauna, Recursos } \\
\text { Naturales y Culturales en las ANPs } \\
\text { - Monitorear flora, fauna, gea, } \\
\text { recursos naturales y culturales } \\
\text { del ANP } \\
\text { - Colaborar en investigación } \\
\text { en las ANPs } \\
\text { - Participar en planificar las ANPs } \\
\text { - Participar en los planes } \\
\text { de incendios forestales } \\
\text { - Prevenir y denunciar acciones } \\
\text { delictivas sobre bienes de } \\
\text { la DRNR }\end{array}$ & $\begin{array}{l}\text { - Ejercer el poder de policía } \\
\text { - Realizar allanamientos } \\
\text { con orden judicial } \\
\text { - Verificar el cumplimiento } \\
\text { de la ley de armas y } \\
\text { explosivos }\end{array}$ & $\begin{array}{l}\text { - Atender a los/las } \\
\text { visitantes } \\
\text { - Participar en } \\
\text { programar y ejecutar } \\
\text { planes de educación } \\
\text { ambiental }\end{array}$ & \\
\hline
\end{tabular}

Fuente: elaboración propia, 2021.

Los/as guardaparques que se incorporan actualmente a la Dirección de Recursos Naturales Renovables poseen título terciario de Técnico/a Superior en Conservación de la Naturaleza o equivalente. Esta formación es brindada en la provincia en el IEF № 9-016 Dr. Jorge E. Coll, a través de sus sedes en los departamentos de Godoy Cruz y Malargüe.

Tanto los/as guardaparques en ejercicio como quiene se encuentran en formación son actores claves en la EAB. Uno de sus pilares fundamentales es la relación con los/as pobladores/as locales, los/as docentes de las escuelas rurales y las escuelas que visitan las ANPs, ya que se encuentran en lugares que son estratégicos para llevar adelante acciones de EAB. A partir de distintas técnicas pudimos relevar información en cuanto a la EAB en las ANPs. Los mapeos de actores mostraron que: 1) se reconoce la responsabilidad clave que tiene la institución donde trabajan (DRNR); 2) se identifican como claves diferentes instituciones vinculadas de manera directa con su trabajo o con el área de la reserva (como municipios, IADIZA, Universidad); 3) se reconoce la relación débil que existe entre guardaparques y pobladores/as, comunidades originarias y científicos/as (Figura 4). Además, durante el proyecto, por medio de las encuestas a guardaparques, se relevó quiénes demandaban educación ambiental y acerca de qué temáticas (Figura 5). 
Figura 4. Síntesis de mapeo de actores en función de su relación con la EAB en las ANPs de Ñacuñán, Bosques Telteca, Laguna del Diamante, Caverna de las Brujas, Laguna de Llancanelo y La Payunia, 2018

\begin{tabular}{|c|c|c|c|c|c|c|}
\hline \multirow[t]{3}{*}{+ poder } & & A UNCuyo & & & $\Delta$ DRNR & \\
\hline & & & & $\Delta$ IADIZA & $\Delta \mathrm{DGE}$ & \\
\hline & & Investigadores/as & & & & \\
\hline \multirow{4}{*}{$\begin{array}{l}\text { Grado } \\
\text { de poder } \\
\text { de los } \\
\text { actores }\end{array}$} & Guardaparques & & A Municipalidad & & & \\
\hline & $\begin{array}{l}\text { Docentes de } \\
\text { escuelas aledañas } \\
\text { al ANP }\end{array}$ & $\begin{array}{l}\text { Pobladores/as } \\
\text { Comunidades } \\
\text { rurales }\end{array}$ & $\begin{array}{l}\text { Organizaciones } \\
\text { ambientalistas }\end{array}$ & Pueblos originarios & & \\
\hline & $\begin{array}{l}\text { Voluntarios/as } \\
\text { TeCoNa }\end{array}$ & $\begin{array}{l}\text { Organizaciones } \\
\text { naturalistas }\end{array}$ & & & & \\
\hline & Visitantes & & & & & \\
\hline \multirow[t]{2}{*}{ - poder } & & & & & & \\
\hline & + afines & \multicolumn{3}{|c|}{ Grado de afinidad con la EAB } & & - afines \\
\hline
\end{tabular}

Figura 5. Sujetos/as de demandas y temáticas para la acción en EAB en las ANPs de Ñacuñán, Laguna del Diamante y Bosques Telteca, 2018

\begin{tabular}{|c|c|c|}
\hline \multirow{7}{*}{$\begin{array}{l}\text { Sujeto de demanda } \\
\text { de acciones de EAB }\end{array}$} & Guardaparques & $\begin{array}{l}\text { Calendario ambiental } \\
\text { Rol del/a guardaparque } \\
\text { Conocer el ANP }\end{array}$ \\
\hline & Docentes & $\begin{array}{l}\text { Currícula escolar } \\
\text { Temáticas ambientales: } \\
\text { Calentamiento global } \\
\text { Reciclaje } \\
\text { Contaminación } \\
\text { Maltrato animal } \\
\text { Mascotismo } \\
\text { Tráfico de fauna } \\
\text { Flora nativa } \\
\text { Fauna silvestre }\end{array}$ \\
\hline & DRNR & \\
\hline & Gobierno Municipal & láticas $\mathrm{n}$ \\
\hline & $\begin{array}{l}\text { Técnico/as } \\
\text { Científico/as } \\
\text { Naturalistas }\end{array}$ & Diversidad biológica \\
\hline & Visitantes de las ANPs & Diversidad biológica y diversidad cultural \\
\hline & Organización externa al tema de EAB & Festejo de la niñez \\
\hline
\end{tabular}

Fuente: elaboración propia, 2018

Respecto de los/as destinatarios/as de las acciones de EAB, en las encuestas realizadas en el año 2018, en las seis ANPs de un total de 64 respondientes, se desprende que el $78 \%$ (50 respuestas) señaló al público en general que visita las ANPs; el 67 \% (43 respuestas), 
a las escuelas aledañas a las ANPs; el $56 \%$ (36 respuestas), a las escuelas que visitan las ANPs; el $45 \%$ (29 respuestas), a los/as pobladores/as locales y vecinos/as; el $30 \%$ (19 respuestas), a cazadores y pescadores provenientes de zonas urbanas; y un $19 \%$ (12 respuestas), a otros sectores.

Es por ello que los objetivos específicos del proyecto fueron brindar instancias participativas, de reflexión sobre sus prácticas en este campo, y de capacitación en contenidos y herramientas que se pudieran adaptar a la realidad de cada ANP. Se entiende que generar acciones de empoderamiento con los/as guardaparques en las cuales el eje consista en la valoración de la diversidad biológica y cultural posibilita estrategias de conservación de la naturaleza más eficaces y con efecto multiplicador en el territorio mendocino.

\section{Diálogos entre la pedagogía freiriana y el enfoque ecosistémico}

Paulo Freire, en su libro ¿Extensión o Comunicación? (2005), plantea dos modalidades de relación entre un sujeto universitario y uno de los sectores populares: los/as agrónomos/ as y los/as trabajadores/as rurales. Aquellas implican una teoría que las sostiene, dirige y condiciona, más allá de que sea explicitada o no. Detrás de la acción puede existir una teoría dialógica o una antidialógica. A partir de ellas, Freire diferencia dos prácticas, una de comunicación sustentada en la primera y una de extensión como concreción de la segunda. Se intenta realizar una traspolación entendiendo que los/as técnicos/as en conservación de la naturaleza trabajan en ámbitos donde interactúan con otros actores sociales, los cuales también le dan un valor simbólico y de uso al territorio, con una historia y un entramado de poder particular. En Mendoza, son los/as puesteros/as o crianceros/as, pueblos originarios, guías de turismo, entre otros.

La extensión "a secas" es entendida como una acción donde existen tres elementos constitutivos: el/la extensionista o sujeto cognoscente, "poseedor del saber", que extiende sus técnicas y saberes a los/as extensionados/as, "ignorantes absolutos", quienes los reciben para mediatizar con los objetos cognoscibles. Los/as primeros/as funcionan en esta lógica como disertantes, expositores/as, frente a estos/as otros/as que resultan espectadores. Termina tratándose de una "invasión cultural", de imposición de un sistema de valores, de la visión del mundo de un sujeto sobre otro. La misma constituye, junto con la conquista, la manipulación y el mesianismo, dimensiones de la teoría antidialógica. Estas acciones conllevan, según Freire, a la domesticación de los sujetos. O aún peor, a la omisión, negación y hasta anulación de las otras personas que son diferentes a uno.

El proceso educativo dejaría de ser, desde esta visión, efectivamente un proceso liberador, para tornarse rígido, dogmático, autoritario, como instrumento de dominación. Desde este análisis, Freire halla dentro del "campo asociativo" del término extensión una relación significativa con "transmisión, entrega, donación, mesianismo, mecanicismo, invasión cultural, manipulación" (Freire, 2008, p. 21).

En este sentido, y acorde al modelo de extensión "difusionista-transferencista" postulado anteriormente, dichos términos implican una visión bancaria de la educación, de los sujetos cognoscentes y de su relación con los objetos cognoscibles. Es entendida en la práctica rural de los agrónomos/as-educadores/as hacia los/as campesinos/as como un proceso de domesticación asistencialista, que no dialoga en el encuentro con dichos sectores, sino que 
transfiere técnicas y herramientas que aprende en la universidad para aumentar la productividad, sin tener en cuenta la cosmovisión de los/as mismos/as y la totalidad compleja en la que se insertan las prácticas agrícola y pedagógica.

En contraposición, la comunicación refiere a un fundamento gnoseológico que concibe el acto cognoscitivo en calidad de relación dialógica entre sujetos cognoscentes en torno a un objeto cognoscible. La intersubjetividad consiste en su característica principal, pues "el sujeto pensante no puede pensar solo: no puede pensar sin la coparticipación de otros sujetos, en el acto de pensar, sobre el objeto" (Freire, 2005, p. 74). Por lo tanto, la relación dialógica se agrega a aquellas gnoseológica, lógica e histórica como constitutivas del conocimiento (Nicol, en Freire, 2005). En la condición del aprendizaje se encuentra, entonces, la reciprocidad de la relación comunicativa, que implica que no puedan existir sujetos pasivos, depositarios, sino cointencionados al objeto de su pensar.

Para que resulte inteligible el diálogo, se requiere que los sujetos compartan un mismo sistema de signos lingüísticos. Puede ocurrir que los/as extensionistas empleen un sistema simbólico ininteligible para los sectores con los que trabajan. Como Freire remarca en su obra: "Nuestro lenguaje técnico, que se expresa en un universo de signos lingüísticos propios, puede no ser comprendido por ellos, como el significante del significado, sobre el cual hablamos" (2005, p. 76). En otras palabras, "la educación es comunicación, es diálogo, en la medida en que no es la transferencia del saber, sino un encuentro de sujetos interlocutores, que buscan la significación de los significados" (p. 77).

En esta comunicación debe estar presente la relación pensamiento-lenguaje-realidad. Ello significa reconocer el contexto, lo cual consiste en una dimensión fundamental del aprendizaje, pues aquel no está exento de las condiciones socioculturales de los sujetos cognoscentes y posibilita la interacción crítica y dialéctica entre aquello que acaece en la propia realidad y su reflexión sobre la misma. A ello se podría adicionar el sentir como un elemento más de dicha relación, es decir, las emociones, la afectividad. Se trata de una dimensión fundamental en las vivencias de los seres humanos, la cual atraviesa, obstaculiza o promueve diversas formas de aprender e interactuar con las otras personas.

El aula, entendida como cualquier espacio donde la relación comunicativa pueda suceder, significa encuentro, siempre amoroso, de varones y mujeres mediatizados/as por el mundo, donde el "quehacer es permanente acto cognoscitivo" (Freire, 2008, p. 91). Es verdadera educación en tanto búsqueda de ser más, en un estar siendo en comunidad, en y con el mundo (Freire, 1970).

Así es que Freire (2005) diferencia una actitud humanista de una humanitarista de los sujetos que, basados en la ciencia y no en la "doxa", afirman la posibilidad de pensar, repensar, crear y cambiar el mundo con otros y otras.

Acorde a esa concepción de la comunicación en términos de diálogos de saberes, de cocreación, donde el saber producido en la academia es valorado en el diálogo con otros saberes, se introduce en el enfoque ecosistémico.

El enfoque ecosistémico (EE), marco base del Convenio de la Diversidad Biológica, incorpora al ser humano como parte del análisis en la elaboración de planes de manejo de ANPs. Esto significa incluir las variables sociales, políticas y económicas como elementos parte (Arguedas Mora, 2012), por lo cual puede leerse como un aliado potente al paradigma de la extensión crítica. 
En este sentido, su principio número once está en sintonía con la extensión crítica al afirmar que en el enfoque ecosistémico "deberían tenerse en cuenta todas las formas de información pertinentes, incluidos los conocimientos, las innovaciones y las prácticas de las comunidades indígenas, científicas y locales" (Arguedas Mora, 2012, p. 14). El mismo asume el saber popular como una fuente de conocimientos válida complementaria al saber científico y que puede aportar en la elaboración de planes de manejo de las ANPs. A ello se adiciona el principio doce:

"En el EE deben intervenir todos los sectores de la sociedad y las disciplinas pertinentes (...). Un proyecto de conservación tiene que manejar temas biológicos y ecológicos, tiene que ver con temas sociales y económicos, con aspectos culturales y formas de vida de poblaciones, con temas espirituales y religiosos y hasta con asuntos de políticas públicas". (Arguedas Mora, 2012, p. 15)

La zonificación de las ANPs es una herramienta clave en la gestión y manejo del territorio y una exigencia en los planes de manejo que se elaboren. Stanley Arguedas Mora, referente de la Escuela Latinoamericana de Áreas Protegidas, recomienda desde la asistencia técnica, la experiencia y el sentido común, que la zonificación de las ANPs sea negociada con los/ as usuarios/as o los sectores afectados directos, por ejemplo, las comunidades que viven dentro del área y los/as propietarios/as privados/as; además de considerar los usos tradicionales que se efectuaban antes de su delimitación (Arguedas Mora, 2013).

A esta perspectiva ontológica y epistemológica se suma una conveniencia logística en cuanto a la gestión de las ANPs. En numerosas ocasiones, la capacidad operativa efectiva en el campo es baja debido al escaso personal en relación a la cantidad de hectáreas alcanzadas para su monitoreo, control y vigilancia. Ello invita a valorar y reconocer la presencia, apoyo y aporte de los/as pobladores/as locales para un mejor manejo. Incluso Stanley Arguedas Mora plantea la importancia de efectuar procesos participativos para realizar zonificaciones de las ANPs empleando técnicas accesibles de grillas y trazo directo por los distintos actores afectados en conjunto con personal técnico para su diseño y validación.

Otro aspecto que considera el trabajo persistente con diversos actores, incluyendo las comunidades, es la definición de zona de influencia en el proceso de zonificación, entendida como "la capacidad de extender la gestión más allá de los límites del AP, en función de lograr un entorno regional más amigable con los objetivos para los que fue creada" (Arguedas Mora, 2013, p. 41).

Entonces, luego de asumir este enfoque que pretende y da proyección a una gobernanza participativa de las ANPs que no es evidente a nivel local, se analiza el proyecto llevado adelante en las ANPs de la provincia de Mendoza desde el paradigma de la "extensión crítica" o "comunicación", en términos de Freire.

\section{El proyecto en el marco de la extensión y pedagogías críticas}

Para realizar un análisis crítico del proyecto, se parte de preguntas coherentes con la perspectiva de la extensión crítica y freiriana. 


\section{La mirada ontológica: ¿entre quiénes?}

En el proyecto existe un punto de partida dialógico donde las voces y representaciones sociales de los/as guardaparques son fundamentales y la materia prima para pensar en conjunto. Es decir, se trata una mirada desde la comunicación, donde las integrantes del equipo entienden que no puede establecerse una relación de poder jerárquica entre "las que saben" y "los/as que no", sino la búsqueda de interactuar, intercambiar y compartir saberes y críticas. No existen salvadores o salvadoras de la educación ambiental, que es una visión que muchas veces también se posee sobre los/as talleristas a cargo de las propuestas.

El punto de partida fue la manifestación de los/as guardaparques de carecer de conocimientos y herramientas para la $\mathrm{EAB}$, considerada como un instrumento para la acción. En este sentido, interpelaron al equipo como académicas poseedoras del saber. $Y$ desde el equipo se buscó rescatar los saberes y experiencias de EAB del cuerpo de guardaparques y valorar y promover una reflexión crítica de las mismas. Se trató de una intencionalidad y vigilancia epistemológica permanente de no caer en el modelo transferencista, para lo cual se ensayaron diversos dispositivos que habilitaran el diálogo. Para ello, se trabajó con técnicas cuantitativas de encuestas y cualitativas de talleres participativos de reflexión, discusión y sistematización grupal.

\section{La mirada situada: ¿dónde?}

Reconocer el contexto llevó el esfuerzo y la insistencia tenaz de invitar a los/as guardaparques de distintas ANPs para poder entender lo local. Se trató entonces de una práctica pedagógica situada, donde la teoría y la práctica se conjugaron en una praxis en espiral: teoría-acción-reflexión-teoría-acción-reflexión. En síntesis: pensamos donde pisamos.

Para ello, en un primer momento se realizaron talleres en cada ANP, y luego se promovió el intercambio de experiencias, se invitó a guardaparques de distintas ANPs y se facilitó que visitaran y vivenciaran los talleres en otras áreas naturales.

En las actividades planteadas en cada ANP se evidenciaron diversos perfiles de grupo, con distinto nivel de interés, tanto individual como grupal, por lo que en algunas ANPs se trabajó con mayor dinámica y predisposición con gran influencia tanto de líderes positivos como negativos.

En cuanto al intercambio entre ANPs, existieron resistencias institucionales que impidieron a ciertos guardaparques de trasladarse y participar y en otros casos habilitaron la participación y disponibilidad de tiempo y espacio en las APNs. También es digno de resaltar que algunos/as guardaparques y técnicos/as en su día de franco se trasladaron más de $500 \mathrm{~km}$ para participar en los talleres.

\section{La mirada pedagógica: ¿cómo?}

Se trabajó de modo federal dentro de la provincia, en tres grupos de investigadoras-extensionistas en tres espacios geográficos diferenciados (norte-centro-sur) según el grado de afinidad y vinculación histórica.

Se planificaron participativamente dentro de la diversidad del equipo de investigación extensión acciones de educación ambiental para la biodiversidad contextualizadas para cada reserva y sus áreas de influencia, fortaleciendo los lazos de trabajo conjunto. Todos los instrumentos metodológicos se elaboraron mediante discusión interna del equipo de 
trabajo, incluyendo las diferentes miradas disciplinares y antecedentes bibliográficos. Cabe mencionar que el cuerpo de guardaparques demandó aunque no intervino en las acciones de planificación de los talleres.

Se propició la reflexión sobre las problemáticas mencionadas y la capacitación de guardaparques en cuanto a la adquisición de estrategias educativas y de diálogo con actores locales.

Se partió del esfuerzo de proponer e incentivar un diálogo de saberes, desde una pedagogía dialógica mediante instancias participativas creativas y dinámicas.

Respecto de las técnicas cuantitativas, se priorizó el estudio de las representaciones sociales de los/as guardaparques sobre diversidad biocultural a través de encuestas en línea. Sin embargo, en algunos casos se imprimieron las encuestas a completar en las ANPs y se volcaron luego al formulario en línea. Con este esfuerzo se lograron reunir 64 encuestas de guardaparques. Todo el material relevado y analizado fue procesado y devuelto al cuerpo de guardaparques con el fin de validar y abrir nuevos debates sobre los resultados.

En el equipo del proyecto hubo una oposición abierta a las "charlas" donde el soporte de programas informáticos para el diseño de presentaciones es el predilecto, dado que este formato centra la atención en quien "tiene el saber" y se corre el riesgo de caer en la teoría antidialógica, donde lo expositivo es la clave y los/as espectadores/as son considerados/as pasivos/as, sin interactuar desde sus saberes, problemáticas y formas de entender y pensar.

Se asume que no existen técnicas buenas o malas en sí mismas, sino que depende del contexto pedagógico en el que son empleadas, por ende, resulta importante entender que la charla es una herramienta más pero no exclusiva y excluyente. Sin embargo, esta herramienta es empleada muy a menudo por los/as guardaparques, que la usan tanto para asegurar un hilo conductor como para generar debates, y corren el riesgo a menudo de imponer valores y una mirada única sobre el mundo de la conservación de la naturaleza.

En efecto, las dinámicas de los talleres que se presentaron, pretendían no solo el trabajo del equipo con los/as guardaparques sino también servir de modelo. Las mismas estimularon el diálogo, preguntas, el relato y la organización de las propias experiencias, donde no se impuso una visión del mundo, sino por el contrario, se habilitó a poder debatir y construir diversas miradas.

La idea fue plantear como novedad que las respuestas y recetas no las tienen "los/as especialistas" sino que las alternativas y bases para propuestas, están en las propias trayectorias que los/as guardaparques han venido transitando. Didácticamente, se pudo contribuir con la organización de sus experiencias y en generar espacios donde pudieran compartirlas a través de la técnica de conversatorios. Dando lugar a que se empoderen en su rol como educadores/as ambientales, y no se sintieran anulados/as, omitidos/as, silenciados/as o subestimados/as, por priorizar otras tareas que tienen a cargo como trabajadores/as de las ANPs (sobre todo tareas de control y vigilancia).

Desde este enfoque se realizaron dos talleres en cada reserva seleccionada. Mediante la reflexión y la adquisición de conceptos y herramientas los/as guardaparques tanto en ejercicio como en formación (estudiantes de la Tecnicatura en Conservación de la Naturaleza), pudieron problematizar y sistematizar sus acciones en educación ambiental para la biodiversidad, ya sea en el ámbito formal como no formal. 
En el taller de cierre del proyecto se empleó la técnica del teatro-foro, que situó a los/as guardaparques como espectactores/as sobre problemáticas de la conservación de la diversidad cultural y biológica. Esta técnica proviene de la pedagogía del oprimido del dramaturgo brasilero Augusto Boal, en sintonía con la pedagogía dialógica de Paulo Freire, donde se busca poder tomar distancia desde afuera de tal o cual situación problemática, en calidad de espectadores/as pero proponiendo a su vez alternativas de solución e involucrándose como nuevos actores en la escena (Boal, 2015; Valoras UC, 2008).

\section{Análisis del material relevado: ¿cómo y por quiénes?}

La postura metodológica estuvo enmarcada en el paradigma interpretativo. Para el análisis se realizó triangulación de la información cuantitativa de las encuestas y cualitativa a través de dinámicas de grupales, de planificación, sistematización y reflexión sobre las experiencias, prácticas y estrategias utilizadas. Los talleres fueron grabados y luego se sistematizaron los resultados. En los mismos las integrantes del equipo se dividieron roles, incluyendo la observación participante como parte de la validación metodológica. La sistematización de experiencias de educación ambiental de los/as guardaparques se relevó en las encuestas y en los talleres realizados en las seis ANPs mencionadas. Siempre se empleó la estrategia de devolución de los datos analizados por entender que es un derecho básico a la información y un respeto hacia los/as guardaparques que dedicaron su tiempo y energía en los talleres.

Otro aspecto a considerar en el desarrollo del proyecto es sobre la forma de recabar los datos y la confección de planillas de sistematización sobre las experiencias de educación ambiental en las ANPs. Se halló que los instrumentos confeccionados y propuestos por el equipo (planillas, grillas) para que los/as guardaparques pudieran continuar con su sistematización de las actividades de EAB que realizarán a posteriori de los talleres no fueron empleados en las ANPs. Por lo cual una posibilidad a plantear a futuro es que la elaboración de las grillas de registro sea realizada por los/as mismos/as guardaparques con el fin de que puedan apropiarse de las mismas y emplearlas de modo sistemático.

\section{Reflexiones finales y perspectivas futuras}

Dentro del equipo se asumió el desafío de colocar en diálogo e interacción las ciencias naturales y las ciencias sociales y se logró el trabajo interinstitucional. Esto es considerado una gran fortaleza de la experiencia dadas las lógicas institucionales tan diversas. Compartir el mismo sistema de signos lingüísticos, dado que las integrantes del equipo son docentes y estudiantes de la Tecnicatura en Conservación de la Naturaleza, permitió emplear términos familiares desde el saber técnico-profesional y construir empatía en torno a las dificultades y amenazas. Esta confluencia de situaciones no es fácilmente alcanzada y en el contexto que pudo ser posible, se logró una muy buena interacción. Sin embargo, y como la otra cara de la moneda, la continuidad del mismo se ha visto afectada por la precariedad laboral de algunas personas del equipo extensionista, como también por situaciones internas y externas propias de las instituciones.

Otro aspecto de relevancia fue el considerar la singularidad y lo local a la hora de encarar las actividades en cada ANP teniendo en cuenta su contexto temporo-espacial. La historicidad es fundamental, ya que habilita a entender los procesos históricos en los que están 
insertas estas ANPs y de ahí buscar estrategias de extensión crítica y educación ambiental. Se pretendió, por tanto, planificar participativamente acciones de EAB contextualizadas para cada reserva y sus áreas de influencia, fortaleciendo los lazos de trabajo conjunto. Se esperó contribuir a la reflexión sobre las problemáticas mencionadas y a la formación de guardaparques en cuanto a la adquisición de estrategias educativas y de diálogo con actores locales.

Asimismo, cabe destacar el logro de haber sistematizado los resultados obtenidos en las áreas protegidas y haberlos compartido en un documento presentado en la Dirección de Recursos Naturales Renovables de la Provincia, en las Jornadas de Áreas Protegidas de Mendoza en los años 2018 y 2019, donde participaron guardaparques, técnicos/as y estudiantes.

La presentación de los resultados no implicó necesariamente un cambio ni mejora institucional respecto de EAB pero, como se mencionó anteriormente, el impulso individual se vio visibilizado y fortalecido.

De continuar el proyecto, se plantean como temas pendientes, la planificación de actividades con las escuelas aledañas a las ANPs, lo cual en algunas áreas protegidas han sido realizadas de modo intermitente por los/as guardaparques de motu proprio. Y, por otro lado, el fortalecimiento de la sistematización de experiencias y la necesaria incorporación de las acciones de educación en los planes operativos anuales. El objetivo debería ser lograr que se consideren con el mismo nivel de importancia que otras tareas.

Si bien la formación de guardaparques es de nivel superior, no siempre es universitaria. En el nivel superior no universitario es necesario fortalecer la función de extensión, como también la investigación, dado que prevalece la docencia sobre estas dos.

En función de los resultados obtenidos, se destaca la preocupación con respecto a la poca valoración del rol del/a guardaparque en la comunidad. En este sentido, se ha expresado la necesidad de mejorar la relación con los/as pobladores/as rurales. Por otro lado, los/as guardaparques manifestaron la necesidad de adquirir más herramientas para realizar educación ambiental sobre temas particulares vinculados a la biodiversidad, como la relación conflictiva con carnívoros y ganado. Y estrategias para poder trabajar en conjunto con docentes de escuelas rurales.

Se entiende necesario profundizar sobre aspectos teóricos y prácticos que se enfoquen en la extensión que se realiza en ANPs y en los actores claves de esta tarea: los/as guardaparques. Su rol como educadores/as ambientales y extensionistas en áreas rurales es previsible esperar sea cada vez más importante.

\section{Referencias bibliográficas}

Arguedas Mora, S. (2012). Aportes técnicos para el diseño y creación de áreas protegidas considerando el Enfoque Ecosistémico. Escuela Latinoamericana de Áreas Protegidas. Universidad para la Cooperación Internacional.

(2013). Reflexiones metodológicas para la zonificación de Áreas Protegidas. Escuela Latinoamericana de Áreas Protegidas. Universidad para la Cooperación Internacional.

Barahona, A.; Llano, C.; Diaz Isenrath, G.; Rojas, L.; Pampillón, C.; Nudelman, L. y Campos, C. (2021). Biodiversity education: resources and sources used by primary school teachers and rangers in Mendoza (Argentina). Multequina, en prensa.

Boal, A. (2015). Teatro del oprimido. Teoría y práctica. Interzona Editora. 
Cannizzo, M.; Campos C. y Lichtenstein G. (2021). Protegiendo lo desprotegido: cambios y desafíos del sistema de áreas naturales protegidas de Mendoza. Boletín de Estudios Geográficos, (114), 53-75.

Freire, P. (1970). Pedagogía del oprimido. Siglo Veintiuno Editores.

- (2005). ¿Extensión o comunicación? La concientización en el medio rural. Siglo Veintiuno Editores.

(2008). La educación como práctica de la libertad. Siglo Veintiuno Editores.

Gonzalez Gaudiano, E. (2002). Educación ambiental para la biodiversidad: reflexiones sobre conceptos y prácticas. Tópicos en Educación Ambiental, 4(11), 76-85.

Llosa, S. (2000). La sesión de retroalimentación de la investigación como espacio de construcción colectiva de conocimientos: una experiencia en la Ribera de Quilmes. En UBA, Análisis político y propuestas pedagógicas. Tomo I. Buenos Aires: Aique.

Neoambiental (2016). 8 Áreas Naturales Protegidas. Mendoza. Programa Mejora de la Gestión Municipal. Gobierno de Mendoza. Secretaría de Ambiente y Ordenamiento Territorial.

Sirvent, M. T.; Toubes, A.; Santos, H.; Llosa, S.; Lomagno, C. (2010). Revisión del concepto de Educación No Formal. Debates y propuestas. Revista del Instituto de Investigaciones en Ciencias de la Educación, (29, sept.). http://repositorio.filo.uba.ar/handle/filodigital/10052

Sousa Santos, B. de (2006, agosto). Capítulo I. La Sociología de las Ausencias y la Sociología de las Emergencias: para una ecología de saberes. En Renovar la teoría crítica y reinventar la emancipación social (encuentros en Buenos Aires). http://bibliotecavirtual.clacso.org.ar/ar/libros/edicion/santos/Capitulo\%20l.pdf

Tommasino, H. y Cano, A. (2016). Modelos de extensión universitaria en las universidades latinoamericanas en el siglo XXI: tendencias y controversias. Universidades, (67, ene.-marz.), 7-24. México.

Tommasino, H. y de Hegedüs, P. (Coords.) (2006). Extensión: Reflexiones para la intervención en el medio urbano y rural. Editorial de la Facultad de Agronomía.

Torres, L.; Claver, S.; Delugan, M. y Abraham, E. M. (2010). Lecciones aprendidas en la gestión de la reserva de biosfera de Ñacuñán y su área de influencia (Mendoza, Argentina). Ciência \& Trópico 34(1), 175-200.

Valoras UC (2008). Teatro foro: soluciones a Conflictos. Ministerio de Educación. Gobierno de Chile.

\section{Normativa}

Ley 6045. Ley de Protección de Áreas Naturales Provinciales (1993). Publicada en el Boletín Oficial, 13 de octubre de 1993. Mendoza.

Ley 7291. Ley de Creación del cuerpo de guardaparques de la provincia de Mendoza (2004). Publicada en el Boletín Oficial, 3 de diciembre de 2004. Mendoza.

Ley 7824. Ley de límites del área natural protegida humedal LLancanelo, departamento Malargüe (2007). Publicada en el Boletín Oficial, 31 de enero de 2008. Mendoza.

\section{Página web}

Áreas Naturales Protegidas. Dirección de Recursos Naturales Renovables. Mendoza. http://www.areasnaturales.mendoza.gov.ar/ 